\title{
Genome-Wide Small Interfering RNA Screening Reveals a Role for Cullin3-Really Interesting New Gene Ligase Signaling in Heterologous Sensitization of Adenylyl Cyclase ${ }^{\mathbb{\$}}$
}

\author{
Zhong Ding, Karin F.K. Ejendal, Monica Soto-Velasquez, Michael P. Hayes, \\ Nicholas Santoro, Martha J. Larsen, and Val J. Watts \\ Department of Medicinal Chemistry and Molecular Pharmacology (Z.D., K.F.K.E., M.S.-V., M.P.H., V.J.W.), Purdue Institute for \\ Drug Discovery (V.J.W.), and Purdue Institute for Integrative Neuroscience (V.J.W.), Purdue University, West Lafayette, Indiana; \\ and Center for Chemical Genomics, University of Michigan, Ann Arbor, Michigan (N.S., M.J.L.)
}

Received July 12, 2019; accepted December 12, 2019

\begin{abstract}
Heterologous sensitization of adenylyl cyclase (AC) is revealed as enhanced or exaggerated AC/CAMP signaling that occurs following persistent activation of $\mathrm{G} \alpha_{\mathrm{i} / \mathrm{o}}$-coupled receptors. This paradoxical phenomenon was discovered more than 40 years ago and was proposed as a cellular mechanism to explain the adaptive changes that occur following chronic exposure to drugs of abuse. However, the underlying molecular mechanisms of heterologous sensitization of $A C$ remain largely unknown. In the present study, we performed a genome-wide cell-based RNA interference screen as an unbiased approach to identify genes associated with heterologous sensitization of AC. Following a series of validation and confirmation assays, three genes that form an E3 ligase complex, cullin3 (CUL3), neural precursorcell-expressed and developmentally downregulated 8 (NEDD8), and really interesting new gene (RING)-box protein 1 (RBX1), were identified as specific modulators of heterologous sensitization of AC. Furthermore, based on the downstream actions of these genes, we evaluated the activity of proteasome inhibitors as well as the specific NEDD8-activating enzyme inhibitor, MLN4924 (Pevonedistat), in AC sensitization. We demonstrate that MG-132 and bortezomib treatments could mimic the inhibitory effects observed with gene knockdown,
\end{abstract}

and MLN4924 was potent and efficacious in blocking the development of heterologous sensitization of endogenous and recombinant $A C$ isoforms, including $A C 1, A C 2, A C 5$, and $A C 6$. Together, by using genetic and pharmacological approaches, we identified, for the first time, cullin3-RING ligases and the protein degradation pathway as essential modulators for heterologous sensitization of AC.

\section{SIGNIFICANCE STATEMENT}

Through a genome-wide cell-based RNA interference screening, we identified three genes that form an E3 ligase complex, cullin3, neural precursor-cell-expressed and developmentally downregulated 8 (NEDD8), and really interesting new gene-box protein 1 , as specific modulators of heterologous sensitization of $A C$. The effect of cullin3, NEDD8, or really interesting new gene-box protein 1 small interfering RNAs on heterologous sensitization was recapitulated by proteasome inhibitors, MG132 and bortezo$\mathrm{mib}$, and the specific NEDD8-activating enzyme inhibitor, MLN4924. These results suggest a novel hypothesis in which protein degradation is involved in the sensitization of $A C$ signaling that occurs following chronic activation of $\mathrm{G} \alpha_{\mathrm{i} / \mathrm{o}}-\mathrm{cou}-$ pled receptors.

\section{Introduction}

Adenylyl cyclases (AC) are enzymes that convert ATP into cAMP. Nine membrane-bound AC isoforms, AC1-AC9, have been identified in mammalian cells. They all share an overall similar structure, which is composed of three intracellular domains (N-terminus and $\mathrm{C} 1$ and $\mathrm{C} 2$ domains) separated by

This work was supported by Department of Medicinal Chemistry and Molecular Pharmacology, the Purdue College of Pharmacy, and the National Institutes of Health [Grants MH101673, MH096927].

https://doi.org/10.1124/jpet.119.261255.

S This article has supplemental material available at jpet.aspetjournals.org. two clusters of six transmembrane helices (M1 and M2). All nine isoforms are stimulated by GTP-bound $\mathrm{G} \alpha_{\mathrm{S}}$ (Dessauer et al., 2017); however, the isoforms are generally divided into four subgroups depending on their distinct regulatory properties. AC1, AC3, and AC8, which belong to subgroup I, are activated by $\mathrm{Ca}^{2+} /$ calmodulin. Subgroup II includes AC2, $\mathrm{AC} 4$, and $\mathrm{AC7}$, which are conditionally activated by $\mathrm{G}_{\beta \gamma}$ in the presence of $\mathrm{G} \alpha_{\mathrm{s}}$. Only AC5 and AC6 are inhibited by physiologic concentrations of $\mathrm{Ca}^{2+}$, and they belong to subgroup III. Whereas isoforms AC1-8 are stimulated by forskolin, AC9 is relatively forskolin insensitive and is the sole member of subgroup IV (Dessauer et al., 2017).

ABBREVIATIONS: AC, adenylyl cyclase; BTB domain, Brc, Ttk, and Bab domain; CRL, cullin-RING ligase; CUL3, cullin3; D2R, D2 dopamine receptor; DN, dominant negative; DOR, $\delta$-opioid receptor; Em, emission; Ex, excitation; GPCR, G protein-coupled receptor; HEK, human embryonic kidney; IBMX, 3-isobutyl-1-methylxanthine; MOR, $\mu$-opioid receptor; NAE, nedd8-activating enzyme; NEDD8, neural precursor-cell-expressed and developmentally downregulated 8; RBX1, RING-box protein 1; RING, really interesting new gene; RT room temperatureScr, Smartpool2; siRNA, small interfering RNA. 
G protein-coupled receptors (GPCRs) convey extracellular signals into intracellular signals via heterotrimeric $G$ proteins. Activation of a $\mathrm{G} \alpha_{\mathrm{s}}$-coupled receptor elicits a stimulatory effect on AC activity, leading to the conversion of ATP into the second messenger cAMP, whereas the activation of $\mathrm{G} \alpha_{\mathrm{i}} /$ $\mathrm{G} \alpha_{0}$-coupled receptors results in an inhibitory effect on AC activity and subsequent cAMP production. However, a study from Dr. Marshall Nirenberg's laboratory in 1975 (Sharma et al., 1975) reported a compensatory increase in AC activity in NG108-15 cells after persistent activation of $\delta$-opioid receptors by morphine. Later, substantial evidence showed that this phenomenon is commonly shared by several other $\mathrm{G} \alpha_{\mathrm{i} / \mathrm{o}_{0}}$-coupled receptors (Watts and Neve, 2005). This response has been referred to by several names, including cAMP overshoot, AC superactivation, and heterologous sensitization of $\mathrm{AC}$, and it has been observed for several, but not all, AC isoforms in a number of cellular models (Cumbay and Watts, 2001). In addition to these in vitro observations, AC sensitization has also been observed in vivo. For instance, repeated injections of D2 dopamine receptor (D2R) or opioid receptor agonists leads to increased AC/cAMP signaling in rodent striatal neurons and the locus coeruleus (Duman et al., 1988; Chester et al., 2006; Aloisi et al., 2011).

A number of mechanistic studies have explored heterologous sensitization as a signaling event involving pathways associated with a variety of GPCR signaling components (Brust et al., 2015). For example, it has been observed that the $\mathrm{G} \alpha_{\mathrm{o}}$ subunit more readily supports sensitization when compared with $\mathrm{G} \alpha_{\mathrm{i}}$ subunit-mediated sensitization by D2R and $\mu$-opioid receptors in NS20Y neuroblastoma (Watts et al., 1998) and C6 glioma cells (Clark et al., 2004), respectively. Studies have also revealed that sequestering G $\beta \gamma$ subunits prevents sensitization of multiple $\mathrm{G} \alpha_{\mathrm{i} / \mathrm{o}}$-coupled receptors (Brust et al., 2015), possibly through modulation of signalosome assembly (Ejendal et al., 2012). Activators of G protein signaling and regulators of $\mathrm{G}$ protein signaling proteins play a modulatory role in AC sensitization as well (Brust et al., 2015). For example, activator of G protein signaling 3 expression has been shown to prevent $\mathrm{G} \alpha_{\mathrm{i} / \mathrm{o}^{-}}$-coupled receptor-induced sensitization in both $\mathrm{CHO}$ and human embryonic kidney (HEK) cells (Sato et al., 2004; Conley and Watts, 2013). Similarly, the involvement of multiple protein kinases in heterologous sensitization has been demonstrated. For example, inhibition of Raf-1 attenuated heterologous sensitization mediated by $\mu$-opioid receptors in CHO cells (Varga et al., 2002) and by prolonged morphine treatment in primary rat dorsal root ganglion neurons (Yue et al., 2008). AC isoform-specific mechanisms have also been reported for which $\mathrm{G} \alpha_{\mathrm{s}}$ is required for the expression of heterologous sensitization of AC5 but not for AC1 (Vortherms et al., 2006). These cell-based observations suggest that the underlying mechanisms of heterologous sensitization of $\mathrm{AC}$ are complex and involve receptor-, G protein-, and AC isoform-specific mechanisms.

In an effort to identify potential novel pathways, we developed and executed a genome-wide cell-based RNA interference (RNAi) screen against $>18,000$ individual genes as an unbiased approach to identify genes associated with heterologous sensitization of AC. HEK cells expressing D2 dopamine receptors in conjunction with AC6 (HEK-AC6/D2 cells) were used as the cellular model system for the screen, and subsequent validation analyses were carried out using both
HEK-AC6/D2 and HEK-D2L cells. Using both cellular models, we validated the requirement of three genes, CUL3, neural precursor-cell-expressed and developmentally downregulated $8(N E D D 8)$, and RING-box protein 1 (RBX1), in regulating heterologous sensitization. These genes are part of the E3 ligase complex, and the effect of CUL3, NEDD8, or RBX1 small interfering RNA (siRNA) transfection was mimicked by proteasome inhibitors MG132 and bortezomib. Moreover, MLN4924 (Soucy et al., 2009), the specific NEDD8-activating enzyme (NAE) inhibitor, also prevented heterologous sensitization of endogenous and recombinant $\mathrm{AC}$ isoforms, including $\mathrm{AC} 1$, $\mathrm{AC} 2, \mathrm{AC} 5$, and $\mathrm{AC} 6$, suggesting that the neddylation pathway, especially the cullin3-RING ligases, may be part of the fundamental mechanism for the development of heterologous sensitization.

\section{Materials and Methods}

\section{Compounds and Other Chemicals Used}

Forskolin, [D-Pen ${ }^{2}$, D-Pen ${ }^{5}$ ] enkephalin, and phorbol 12-myristate 13-acetate were purchased from Tocris (Ellisville, MO). MLN4924 was purchased from Cayman Chemical (Ann Arbor, MI). HEPES and EDTA were purchased from Fisher Scientific (Pittsburg, PA). Quinpirole, spiperone, [D-Ala ${ }^{2}, \mathrm{~N}-\mathrm{MePhe}^{4}$, Gly-ol]-enkephalin (DAMGO), naloxone, naltrindole, A23187, 3-isobutyl-1-methylxanthine (IBMX), Tween 20, Triton X-100, $\mathrm{MgCl}_{2}$, Tris, and beta-cyclodextrin were purchased from Sigma-Aldrich (St. Louis, MO). pcDNA3-myc-CUL3 was a gift from Yue Xiong (plasmid 19893; Addgene), and pcDNA3DN-hCUL3-FLAG was a gift from Wade Harper (plasmid 15820; Addgene).

\section{Cell Culture}

HEK293 cells stably expressing the D2L receptor (HEK-D2L), AC1 with the D2L receptor (HEK-AC1/D2), AC2 with the D2L receptor (HEK-AC2/D2), AC5 with the D2L receptor (HEK-AC5/D2), AC6 with D2L receptor (HEK-AC6/D2), or AC5 with the MOR1 receptor (HEKAC5/MOR1) were maintained in DMEM (Gibco, Thermo Fisher Scientific) supplemented with $5 \%$ fetal clone I serum (Hyclone, Logan, UT), $5 \%$ bovine calf serum (Hyclone), $1 \%$ Antibiotic-Antimycoctic (Life Technologies), and puromycin (Sigma) (HEK-D2L) or puromycin and G418 (Sigma) (HEK-AC1/D2, HEK-AC2/D2, HEK-AC5/D2, HEK-AC6/ D2, HEK-AC5/MOR1). NG108-15 cells were maintained in DMEM supplemented with $2 \%$ glutamine (Sigma) and $10 \%$ fetal bovine serum (Hyclone). All cell lines were cultured at $37^{\circ} \mathrm{C}$ with $5 \% \mathrm{CO}_{2}$.

For cryopreservation, cells were harvested with nonenzymatic cell dissociation buffer, resuspended in cell culture media, and centrifuged for 5 minutes at $500 \mathrm{~g}$. Cell pellet was resuspended in FBS supplemented with 10\% DMSO (Sigma), and cell suspension was aliquoted and frozen gradually. Frozen cells were stored in liquid $\mathrm{N}_{2}$ until use.

\section{siRNA Screening at the University of Michigan Center for Chemical Genomics}

RNAi Library and Cell Plating. The genome-wide cell-based RNAi high-throughput screen was conducted in collaboration with the Center for Chemical Genomics at the University of Michigan, and the data were uploaded to MScreen (Jacob et al., 2012) for its analysis and storage. The screen was performed using the Dharmacon human whole siGENOME SMART-POOL library (GE Healthcare). A nontargeting siRNA control, Smartpool2 (Scr), and a $\mathrm{G} \alpha_{\mathrm{s}}$-targeting siRNA (GNAS siRNA) were used as negative and positive controls, respectively. Positive and negative siRNA controls were included on each plate, and each library plate was screened as independent triplicates. All siRNAs were spotted and assayed in sterile tissue culture-treated 384-well assay plates (part 6007688; PerkinElmer, Boston, MA) using 
the Biomek FX (Beckman Coulter, Fullerton, CA). Lipofectamine RNAiMAX (Thermo Fisher Scientific) was diluted in Opti-MEM, incubated for 5 minutes at RT, and added to the siRNA-spotted plates using an automated dispenser (Multidrop Combi; Thermo Fisher Scientific). Following a 30-minute incubation at RT, cryopreserved HEK293 cells expressing rat AC6 and human D2 dopamine receptor (HEK-AC6/D2) were thawed, counted, and dispensed to the siRNAand Lipofectamine-containing plates using the Multidrop Combi. The plates were centrifuged briefly and then incubated for approximately 70 hours in a humidified incubator at $37^{\circ} \mathrm{C}$ with $5 \% \mathrm{CO}_{2}$. The final concentrations per well were $40 \mathrm{nM}$ siRNA, $0.072 \mu \mathrm{l}$ RNAiMAX, $10 \%$ heat-inactivated FBS (Hyclone), and 1000 cells (HEK-AC6/D2) in a total volume of $30 \mu l$.

Heterologous Sensitization and cAMP Accumulation Measurements. To induce heterologous sensitization, the cells were subjected to either vehicle or the $\mathrm{D} 2 \mathrm{R}$ agonist, quinpirole ( $1 \mu \mathrm{M}$ final concentration), for 2 hours at $37^{\circ} \mathrm{C}$ with $5 \% \mathrm{CO}_{2}$. The plate was equilibrated to RT for 30 minutes before stimulation of cAMP accumulation by the addition of forskolin in the presence of the D2R antagonist, spiperone ( $1 \mu \mathrm{M}$ final concentration), and the phosphodiesterase inhibitor, IBMX (Sigma) $(500 \mu \mathrm{M}$ final concentration). After 1 hour of forskolin-mediated stimulation, the volume was reduced to $15 \mu \mathrm{l}$, and cell viability was measured by adding $5 \mu \mathrm{l}$ CellTiter-Fluor (Promega, Madison, WI), resuspended according to the manufacturer's protocol. After 1 hour incubation at RT with the CellTiterFluor, fluorescence (Ex 390/20, Em 505/20) was measured with the PHERAstar plate reader (BMG Labtech, Cary, NC). After a total forskolin-mediated stimulation time of 2.5 hours, the reaction was stopped by the addition of the homogenous time-resolved fluorescence cAMP detection reagents, d2-labeled cAMP and Cryptatelabeled anti-cAMP antibody (Cisbio, Bedford, MA). Fluorescence (Ex 330/80, Em 615/10 and 665/7) was measured on the EnVision 2104 Multilabel Reader (PerkinElmer Inc.) after 1 hour incubation with the cAMP reagents at RT. To determine the relative cAMP accumulation per well, the ratio of $665 \mathrm{~nm} / 615 \mathrm{~nm}$ fluorescence values was calculated.

Data Analysis. For analysis, data were computed for siRNA samples and controls on the screening plates using the ratio of fluorescence signal emitted at $665 \mathrm{~nm}$ over $615 \mathrm{~nm}$. Data were uploaded to MScreen and analyzed. The computed data for the siRNA sample wells was reported as percentage (\%) activity normalized to the negative control wells ( $0 \%$ activity) and the positive control wells (100\% activity). The resulting \% activity was further normalized to cell viability, calculated by normalizing the computed Cell-Titer Fluor data per well to lysed cells (0\% viability) and the nontargeting Scr (100\% viability). Knockdown of genes that reduced the heterologous sensitization phenotype of AC6 by at least $60 \%$ but did not reduce cell viability by more than $40 \%$ in two out of the three replicates were selected as hits. This resulted in a hit set of 607 genes (3.4\%). From this set, 140 genes were selected for further validation using the four individual siRNAs contained in the pooled siRNAs used for screening (siGENOME; Dharmacon).

\section{SiRNA Validation}

Individual siRNAs targeting the 140 genes were diluted in OptiMEM and manually added to sterile tissue culture-treated 384-well assay plates (PerkinElmer). Lipofectamine RNAiMAX (Thermo Fisher Scientific) was diluted in Opti-MEM media, incubated for 5 minutes, and added to the siRNA-containing plates. Mixture of Lipofectaimine and siRNAs was incubated at RT for 30 minutes. Cells were thawed, rinsed, and resuspended in prewarmed Opti-MEM, counted in an automated cell counter (Invitrogen), and added to the plates. The final concentrations per well were $40 \mathrm{nM}$ siRNA, $0.072 \mu \mathrm{l} /$ well RNAiMAX, 10\% heat-inactivated FBS, and 1000 HEK-AC6/D2 cells in a total volume of $30 \mu \mathrm{l}$. Then, the plates were incubated for approximately 72 hours in a humidified incubator at $37^{\circ} \mathrm{C}$ with $5 \% \mathrm{CO}_{2}$.

\section{DNA Plasmid Transfection}

Briefly, DNA plasmids were first diluted in Opti-MEM to the desired concentrations. Lipofectamine 2000 (Thermo Fisher Scientific) was diluted in Opti-MEM according to the manufacturer's suggested ratio of Lipofectamine/DNA and incubated for 5 minutes. DNA and Lipofectamine solutions were mixed, followed by incubation at RT for 30 minutes, and added to the cells dropwise. Cells were transfected for approximately 48 hours prior to being used for the cAMP/immunoblot assays.

\section{cAMP Accumulation in Cells}

To induce heterologous sensitization of AC, the cells were subjected to either vehicle or the indicated $\mathrm{G} \alpha_{\mathrm{i}}$-coupled receptor agonist for the indicated time in the incubator $\left(37^{\circ} \mathrm{C}\right.$ with $\left.5 \% \mathrm{CO}_{2}\right)$. Then, cells were incubated at $\mathrm{RT}$ for 1 hour after the addition of the respective AC activators in the presence of the indicated $\mathrm{G} \alpha_{\mathrm{i}}$-coupled receptor antagonist and IBMX (500 $\mu \mathrm{M}$ final concentration). The reaction was stopped by the addition of the HTRF cAMP detection reagents (Cisbio). To examine acute activity of ACs, cells were incubated at RT for 1 hour after the addition of the selective AC stimulants in the presence of IBMX. For time course experiments, cells were treated with $2.5 \mu \mathrm{M}$ spiperone to inhibit D2R-mediated signaling at the indicated time point, followed by stimulation with $1 \mu \mathrm{M}$ forskolin. Reactions were stopped by the addition of the Cisbio cAMP detection reagents. After the addition of the cAMP reagents, the plates were incubated for 1 hour at RT, and fluorescence (Ex 330/80, Em 615/10, and 665/7) was measured on a Synergy 4 (Biotek) plate reader. To determine the cAMP values, the $665 / 620$ ratio was calculated, and cAMP accumulation per well was computed by extrapolating the ratio from a standard curve of known concentrations of cAMP.

\section{Cell Viability Assays}

Cell viability assays were conducted for the HEK-AC6/D2 cells following siRNA transfection or drug incubation protocols as previously described in cAMP Accumulation in Cells. The CellTiter-Fluor kit from Promega was used according to the manufacturer's instructions to measure viability of the cells. After 1 hour incubation at RT with the Cell-Titer Fluor reagent, fluorescence (Ex 390/20, Em 505/20) was measured using the Synergy 4 . Cell viability was reported as percentage (\%) of vehicle (100\% viability) and the negative control, $2 \%$ Triton $\mathrm{X}-100$ (0\% viability).

\section{Immunoblot Quantification Analysis}

Cells were harvested from six-well plates and resuspended in prewarmed Opti-MEM 48 and 72 hours after DNA plasmid or siRNA transfection, respectively. A small fraction of cells was plated in a 384well plate for functional assays, and the rest of the cells were used for the immunoblot analysis. Cells were rinsed with ice-cold PBS, resuspended in radioimmunoprecipitation assay buffer $(150 \mathrm{mM}$ $\mathrm{NaCl}, 1 \%$ Triton X-100, 50 mM Tris-HCl, $\mathrm{pH} 7.6,0.1 \%$ SDS, $0.5 \%$ sodium deoxycholate) supplemented with protease inhibitor cocktail (Sigma), and incubated on ice for 30 minutes. The protein concentration was determined using a BCA assay kit (Pierce, Thermo Fisher Scientific) according to the manufacturer's instructions. Samples were prepared in protein-loading buffer (100 mM Tris-HCl, $\mathrm{pH} \mathrm{6.8,}$ $6 \%$ sucrose, 2\% SDS, 5\% 2-mercaptoethanol, 0.01\% bromophenol blue), diluted to desired concentration, and boiled at $100^{\circ} \mathrm{C}$ for 5 minutes. Then, protein samples were loaded onto a $4 \%-15 \%$ precast gradient polyacrylamide gel (BIO-RAD, Hercules, CA) to separate the proteins by SDS-gel electrophoresis. Proteins were transferred from the gel onto a PVDF membrane (Millipore, Bedford, MA) that was blocked with $5 \%$ nonfat milk dissolved in Tris-buffered saline/Tween 20 at RT for 30 minutes. Proteins were detected with anti-G $\alpha_{\mathrm{s}} /_{\mathrm{olf}}(\mathrm{C}-18$; Santa Cruz Biotechnology, TX), anti-cullin3 (SAB4200180; Sigma), anti-NEDD8 (Y297; Abcam), anti-RBX1 [EPR6850(B); Abcam], antiactin (A2066; Sigma), anti-Myc (9B11; Cell Signaling), and anti-flag 
(F7425; Sigma) primary antibodies followed by secondary antibodies, goat anti-mouse IgG (925-68070; LI-COR) or goat anti-rabbit IgG (92532211; LI-COR). The blotted membranes were scanned with an Odyssey CLx (LI-COR), and the intensity of the bands was quantified by using Image Studio Software (LI-COR).

\section{Statistical Analysis}

All data are presented as mean \pm S.E.M. $(n \geq 3)$. Comparisons between two groups were done using Student's $t$ test (e.g., immunoblot quantification). Comparisons among multiple groups under one condition were done using one-way ANOVA (e.g., cAMP assays in dose-dependent gene experiments), and comparisons among multiple groups under two different conditions were performed using two-way ANOVA (e.g., cAMP assay after drug pretreatment) to determine significant differences. The threshold for statistical significance was set at $P<0.05$, and Dunnett's, Tukey's, and Bonferroni's multiplecomparison test were used as indicated in the legends for post hoc analyses. For time course experiments, at each time point, unstimulated (no forskolin) vehicle-treated (no quinpirole) cells were normalized to $0 \%$, and forskolin-stimulated vehicle-treated cells (no quinpirole) were normalized to $100 \%$ activity.

\section{Results}

Development and Execution of a Cell-Based RNAi Genome-Wide Screen for Regulators of Heterologous Sensitization of AC. Heterologous sensitization of AC is an adaptive phenomenon that occurs following persistent activation of $\mathrm{G} \alpha_{\mathrm{i} / 0}$-coupled receptors. The present study used HEK293 cells stably expressing the D2 dopamine receptor in conjunction with AC6 (HEK-AC6/D2 cells) as a model for genome-wide siRNA screening. Persistent activation of the D2R with quinpirole (2-hour pretreatment) followed by stimulation of AC6 with forskolin revealed a robust enhancement of cAMP accumulation (Fig. 1A). The concentration response curve for forskolin-stimulated cAMP accumulation in quinpiroletreated cells was markedly left-shifted with no change in the maximal response. Inspection of the dose response further showed that quinpirole treatment produced a heterologous sensitization response that was enhanced $\geq 15$-fold over vehicle-treated cells at $300 \mathrm{nM}$ forskolin, providing for selective stimulation of AC6 in HEK293 cells (Fig. 1A). Prior to initiating the genome-wide siRNA screen, we confirmed the appropriate activity of our positive control, GNAS-targeting siRNA, and negative control nontargeting (scrambled, Scr siRNA) in heterologous sensitization of AC in HEK-AC6/D2 cells and showed that the sensitization response was silenced by $>95 \%$ following GNAS siRNA transfection (Fig. 1B). Furthermore, immunoblot analysis using an anti-G $\alpha_{\mathrm{s}}$ antibody verified that the expression of $\mathrm{G} \alpha_{\mathrm{s}}$ protein was markedly reduced following GNAS siRNA transfection (Fig. 1C). Based on these assay characteristics, this cellular model and control siRNAs were used to further guide the optimization efforts to develop the siRNA screening assay protocol, subsequently used for the screen.

The human siGENOME library (Dharmacon, GE Healthcare) consists of pooled siRNAs targeting 18,110 genes, which were formatted into 384-well tissue culture plates. In addition, each plate contained nontargeting scrambled negative controls and positive controls targeting GNAS. The screening assay displayed robust metrics with at least an eightfold assay window between positive and negative controls and an average plate $\mathrm{Z}$ ' factor of 0.62 . In addition to cAMP measurements, each well was also initially assessed for cell viability using a nonlytic assay (CellTiter-Fluor; Promega) to exclude those siRNAs that reduced cAMP accumulation as a result of cell death. For data analysis of cAMP accumulation, the wells treated with the siRNA library were normalized between the negative controls (nontargeting, Scr) at $0 \%$ and positive controls (targeting GNAS) at $100 \%$.

Validation of siRNA Screen. To identify potential hits from the screen, we selected genes for which both the heterologous sensitization of AC6 was inhibited by at least $60 \%$ relative to the positive control (100\% reduction) and the cell viability was at $\geq 60 \%$ in at least two out of three replicates. This analysis resulted in a hit set of 607 genes (3.4\%) that was subsequently trimmed to 140 genes largely based on robust inhibition of sensitization as well as elimination of genes involved in essential cell functions and metabolism. The
A

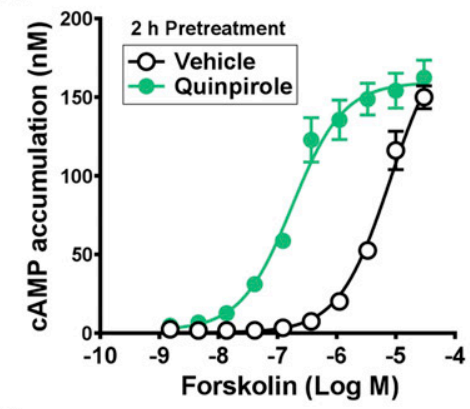

B

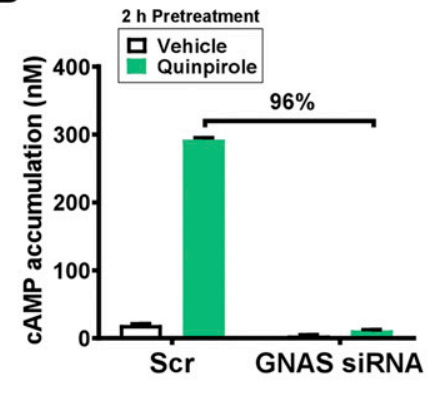

C

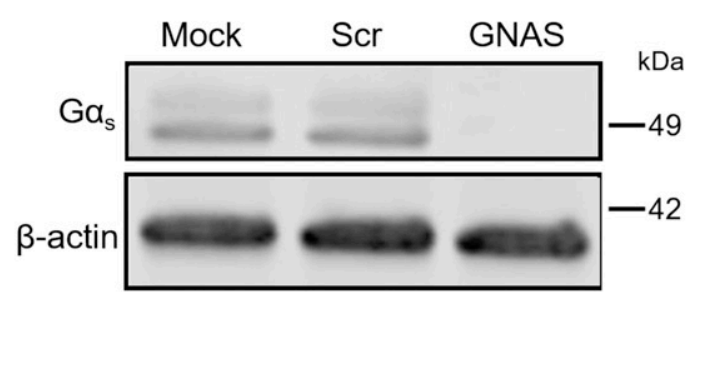

D

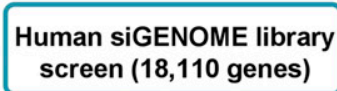

Determine hits from the screen (607 genes)

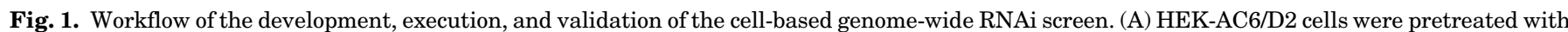

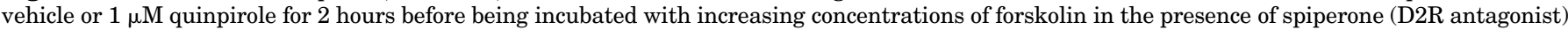

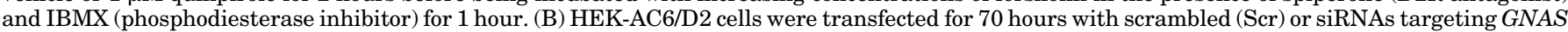

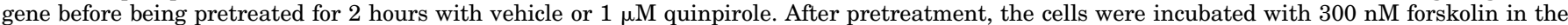

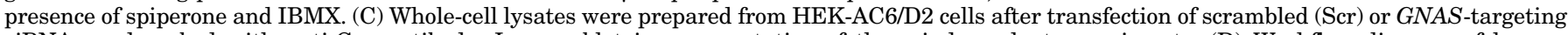

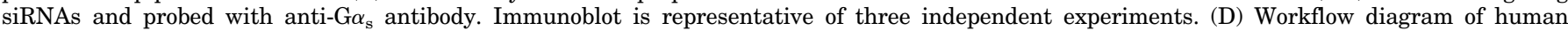
genomewide RNAi screen and the subsequent validation assays. 
140 genes selected for screen validation and analysis were subjected to follow-up assays using four individual siGENOME siRNAs (Dharmacon, GE Healthcare). Our initial validation study for the selected 140 genes was carried out in high-throughput format against HEK-AC6/D2 cells. A surprisingly low number of genes validated, for which at least two of the four individual siRNAs reduced heterologous sensitization of AC6 by more than 50\% (Supplemental Table 1). From the genes that validated, we identified NEDD8 and CUL3 as related genes for which neddylation of cullin3 activates the cullin3 complex, leading to E3 ligase activity (Hori et al., 1999). Identification of this potential pathway prompted us to reanalyze our genome-wide screening effort, in which we found that the siRNA targeting for an additional member of the cullin3 E3 ligase complex, RBX1 (Seol et al., 1999), also reduced sensitization of AC6 by nearly $60 \%$.

Knockdown of $C U L 3, N E D D 8$, or $R B X 1$ Genes Abolished Heterologous Sensitization of AC. The proteins encoded by $C U L 3, N E D D 8$, and $R B X 1$ are intimately linked and are part of activated cullin 3 complexes. The genes in this E3 ligase complex were further validated using the ONTARGET plus siRNA, a line of siRNAs with reduced false positives compared with siGENOME siRNAs (Dharmacon, GE Healthcare). These experiments confirmed that the four individual siRNAs targeting each of the three genes (CUL3, NEDD8, and RBX1) resulted in 50\%-98\% inhibition of heterologous sensitization in HEK-AC6/D2 cells (Supplemental Fig. 1, A-C). Moreover, one of the four individual siRNAs targeting $N A E$ E1 subunit 1 (also known as amyloid precursor protein-binding protein 1) and ubiquitin-like modifier-activating enzyme 3 (also known as NAE E1 catalytic subunit), which compose the specific E1 enzyme for the activation of NEDD8, resulted in up to
70\%-95\% inhibition of heterologous sensitization in HEKAC6/D2 cells (Supplemental Fig. 1D).

Consistently, the ON-TARGET plus-pooled siRNAs targeting $C U L 3, N E D D 8$, or $R B X 1$ genes also abolished heterologous sensitization in HEK-AC6/D2 cells (Fig. 2B). Immunoblot analysis for cullin3 (protein encoded by CUL3 gene) showed a marked reduction of total cullin 3 and neddylated cullin3 protein levels by the pooled CUL3 and NEDD8 siRNAs, respectively (Fig. 2C). Similarly, immunoblot analysis for nedd8 (protein encoded by NEDD8 gene) showed a decrease of both free NEDD8 and NEDD8-conjugated proteins following transfection of the pooled NEDD8 siRNAs (Fig. 2C). Lastly, immunoblot analysis for rbx1 (protein encoded by $R B X 1$ gene) showed a significant reduction in protein expression 72 hours following the transfection of the pooled $R B X 1$ siRNAs (Fig. 2D). In addition to cAMP measurements, cell viability was also measured using a nonlytic assay (CellTiter-Fluor; Promega) after $C U L 3, N E D D 8$, or $R B X 1$ targeting siRNA transfection. Consistent with our screening data, the cell viability was greater than $70 \%$ (Supplemental Fig. 2A). These observations prompted the use of the ON-TARGET plus-pooled siRNAs for the remainder of the studies described below.

There are a total of seven cullin family members and two RING-box proteins. Thus, we examined the specificity of our identified target genes by transfecting pooled siRNAs targeting CUL1, CUL2, CUL4A, CUL4B, CUL5, CUL7, or RBX2 genes into HEK-AC6/D2 cells for studies of heterologous sensitization. Although a modest reduction was observed following CUL2 siRNA transfection, the siRNAs targeting the other cullins had no effect, indicating that cullin3 and RBX1 are selective mediators for heterologous sensitization of AC6 (Supplemental Fig. 2B). Moreover, immunoblot analysis
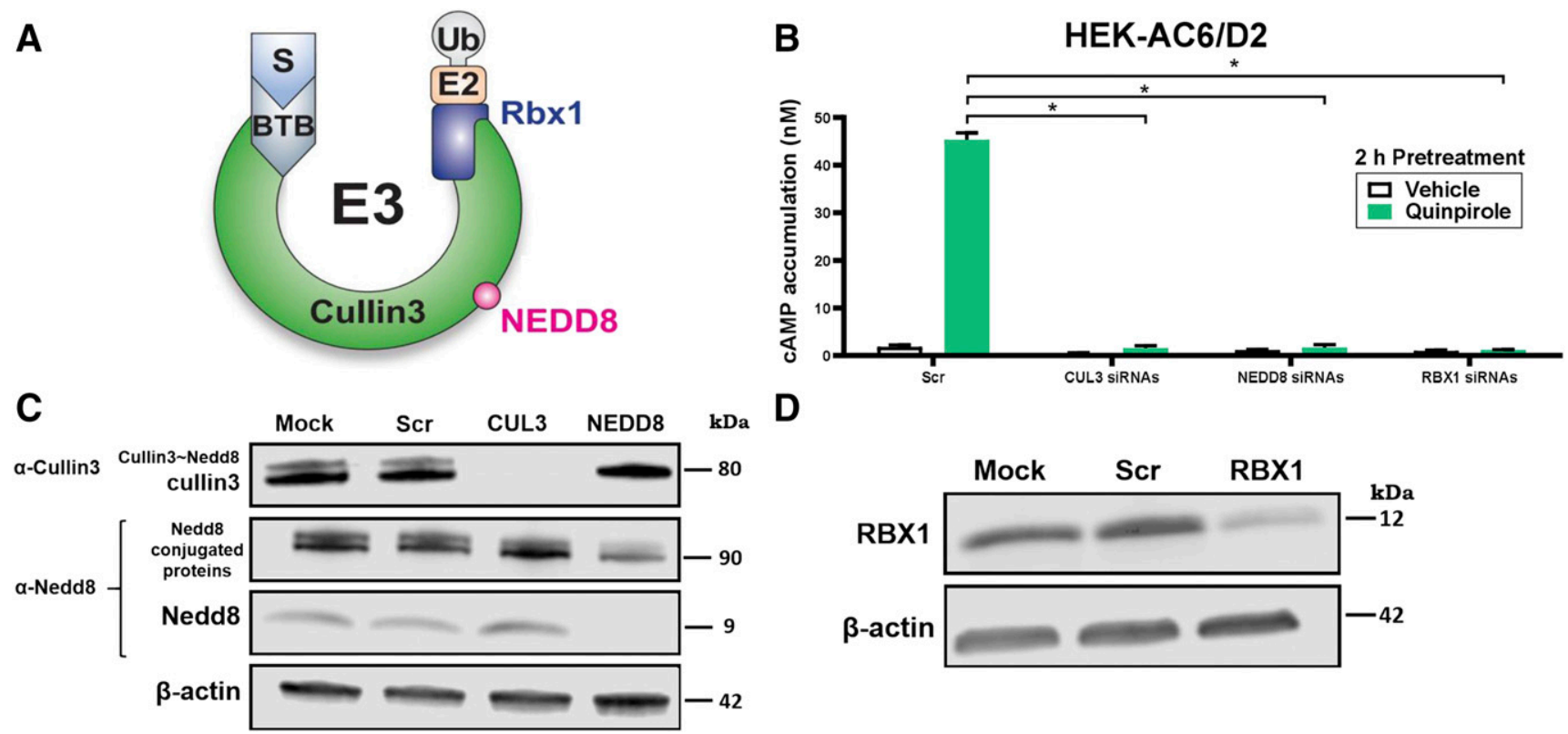

Fig. 2. Effect of siRNA for $C U L 3, N E D D 8$, or RBX1 genes on heterologous sensitization of AC and their protein expression. (A) Diagram of the cullin3RING E3 ligase complex. S, substrate; BTB, BR-C, TTK, and BAB domain; Ub, ubiquitin. (B) HEK-AC6/D2 cells were transfected with scrambled (Scr) or pooled siRNAs targeting the CUL3, NEDD8, or RBX1 genes for 72 hours. Cells were pretreated for 2 hours with vehicle or $1 \mu \mathrm{M}$ quinpirole. After pretreatment, the cells were incubated with $50 \mathrm{nM}$ forskolin in the presence of $1 \mu \mathrm{M}$ spiperone and $500 \mu \mathrm{M}$ IBMX for 1 hour. Whole-cell lysates were prepared from HEK-AC6/D2 cells after transfection of scrambled (Scr) or indicated siRNAs and probed with anti-cullin3 (C), anti-NEDD8 (C), or antiRBX1 (D) antibodies. Immunoblots are representative of three independent experiments. ${ }^{*} P<0.0001$. Two-way ANOVA followed by Tukey's test. 
for $\mathrm{G} \alpha_{\mathrm{s}}$, which plays a pivotal role in regulating heterologous sensitization (Vortherms et al., 2006), ruled out the possibility that the CUL3 siRNA transfection affected the protein expression level of $\mathrm{G} \alpha_{\mathrm{s}}$ and subsequently resulted in the reduction of heterologous sensitization of AC (Supplemental Fig. 2C).

Effect of CUL3, NEDD8, or RBX1 Genes on Acute D2 Dopamine Receptor and AC Activity. Heterologous sensitization requires persistent $\mathrm{D} 2 \mathrm{R}$ activation and is blocked by receptor antagonists or pertussis toxin that prevent acute receptor signaling (Watts and Neve, 1996). Thus, we examined the effect of siRNA transfection for CUL3, NEDD8, or RBX1 on acute D2R signaling. Following 72 hours transfection, the ability of the D2R agonist quinpirole to inhibit forskolinstimulated cAMP accumulation was examined. The results of these studies revealed that transfection of the pooled siRNAs failed to alter the ability of quinpirole to activate the D2R, as no significant reduction in inhibition of AC activity was observed compared with mock or scrambled siRNA-transfected cells (Supplemental Fig. 3A). We did, however, observe a decrease in forskolin-stimulated cAMP accumulation following siRNA transfection. Conditions leading to a reduction in cullin3, nedd8, and rbx1 protein expression also resulted in a decrease in the activity of AC6 following stimulation by forskolin (Supplemental Fig. 3B).

Examination of Cullin3 Gene-Dose Studies for Heterologous Sensitization. We explored further the role of cullin3 through a series gene-dose experiments. We transfected increasing quantities of pooled CUL3 targeting siRNAs into HEK-AC6/D2 cells revealing a dose-dependent decrease in heterologous sensitization of AC6 and protein expression of cullin3 (Fig. 3A). Similarly, transfection of increasing amounts of a flag-tagged dominant negative cullin3 (DN-CUL3) DNA plasmid (Jin et al., 2005) dose-dependently decreased heterologous sensitization (Fig. 3B).

To complement our cullin3 inhibitory studies, we also examined the effect of increased cullin3 expression on heterologous sensitization of AC6. HEK-AC6/D2 cells were transiently transfected with increasing amounts of myc-tagged
A

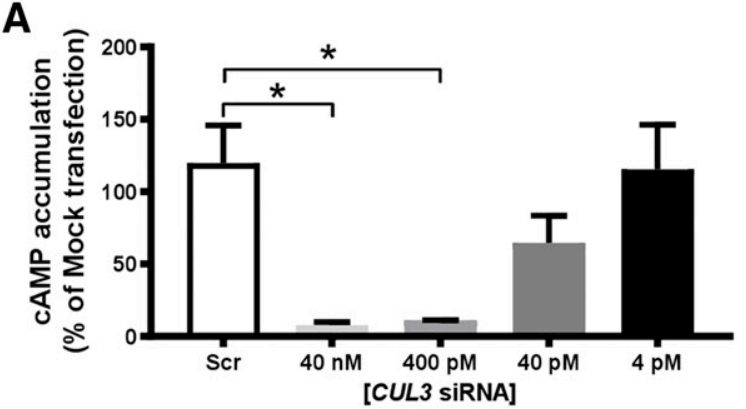

B

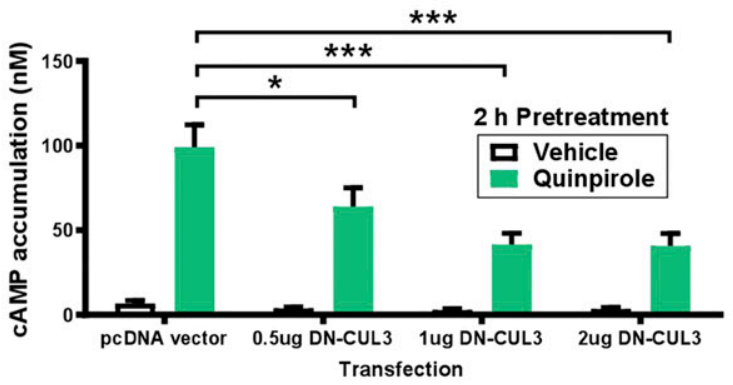

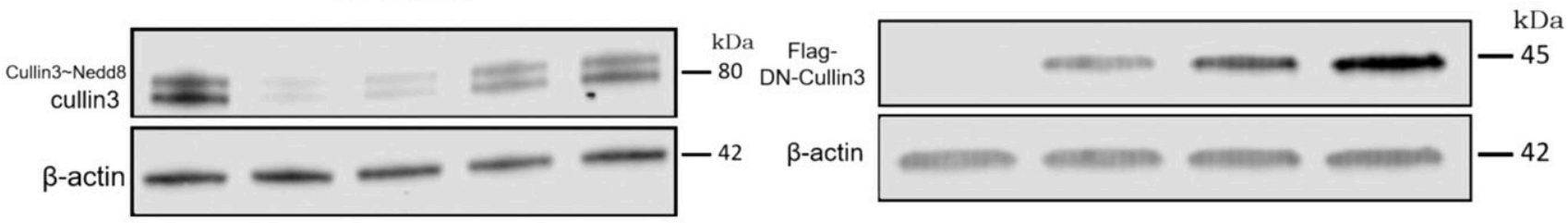

C
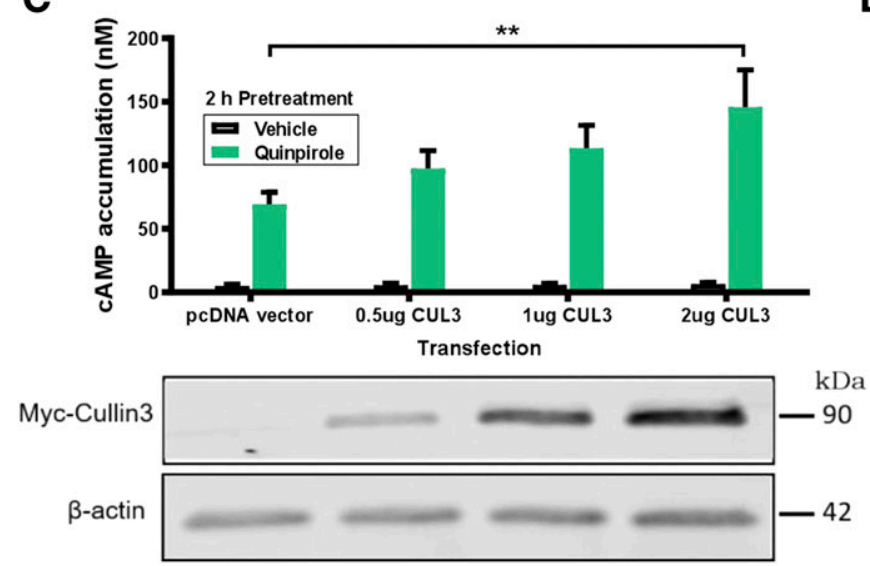

D

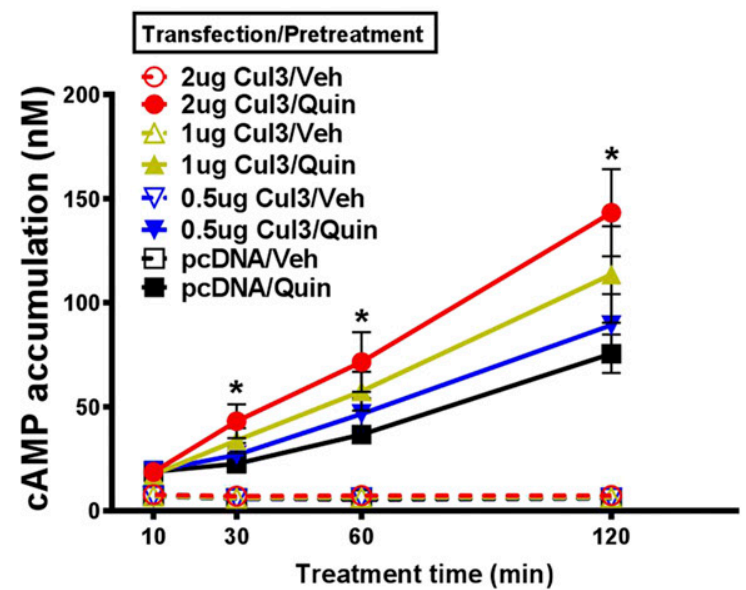

Fig. 3. Analysis of gene-dose effects of cullin3 on heterologous sensitization of AC. HEKAC6/D2 cells were transfected with scrambled (Scr) or control vector (pcDNA 3.1+) and increasing quantities of CUL3 siRNA (A), Flag-DN-CUL3 DNA (B), or Myc-CUL3 DNA (C and D) as indicated. At 72 hours post-siRNA transfection or 48 hours post-DNA transfection, cells were pretreated for 2 hours (A-C) or indicated time (D) with vehicle or $1 \mu \mathrm{M}$ quinpirole before incubating with $50 \mathrm{nM}$ forskolin in the presence of $1 \mu \mathrm{M}$ spiperone and $500 \mu \mathrm{M}$ IBMX for 1 hour. Whole-cell lysates were prepared from HEK-AC6/ D2 cells following the transfection conditions noted in panel above and probed with anti-cullin3 (A), anti-flag (B), or anti-myc (C) antibodies. Immunoblots are representative of three independent experiments. ${ }^{*} P<0.05 ; * * P<0.01 ; * * P<0.001$. One-way ANOVA followed by Dunnett's test (A). Two-way ANOVA followed by Tukey's test (B and C). (D) $* P<0.05$ vs. pcDNA 3.1+/Quin. Two-way ANOVA followed by Tukey's test. 
cullin3 DNA plasmid (Ohta et al., 1999), revealing a dosedependent increase in the magnitude of heterologous sensitization of AC6 (Fig. 3C). Time course experiments further demonstrated that increasing cullin 3 expression also allowed for sensitization to develop at earlier time points (Fig. 3D). Taken together, the loss of heterologous sensitization after transfection of targeting siRNAs or DN-CUL3 DNA and the increase of heterologous sensitization upon overexpression of cullin3 provide evidence that the CUL3 gene functions as an essential regulator of heterologous sensitization of AC.

Examine the Role of Ubiquitination-Proteasome System in the Development of Heterologous Sensitization of Endogenous AC and AC6. To explore the applicability of these findings to physiologic levels of $\mathrm{AC}$, we verified that siRNA transfection for CUL3, NEDD8, or RBX1 also abolished heterologous sensitization of endogenous AC using HEK-D2L cells (Fig. 4A). Cullin3-RING ligases belong to the largest family of E3 ubiquitin cullin-RING ligases (CRLs), which plays a pivotal role in mediating protein ubiquitination. Because proteasome-involved protein degradation is the destination of most ubiquitinated proteins, we examined the effects of two commonly used proteasome inhibitors, MG-132 and bortezomib, in the development of heterologous sensitization of endogenous $\mathrm{AC}$ and AC6. Our results showed that 30 minutes pretreatment with MG-132 or bortezomib significantly blocked quinpirole/D2R-induced heterologous sensitization of endogenous AC (Fig. 4B) and AC6 (Fig. 4C). These data are consistent with a role for proteasome-mediated protein degradation in heterologous sensitization of AC.

MLN4924 Blocked the Development but Not the Expression Phase of Heterologous Sensitization of AC. Although MG-132 and bortezomib significantly inhibited heterologous sensitization of AC, they are nonspecific inhibitors for the ubiquitination-proteasome system. In addition, the targeting siRNAs for CUL3, NEDD8, or RBX1 genes attenuated acute AC6 activity as well (Supplemental Fig. 3B).
Both observations prompted us to further validate pharmacologically the specific role of cullin3-RING ligases in regulating heterologous sensitization of AC. Taking advantage of the NAEspecific inhibitor MLN4924 (Pevonedistat) (Soucy et al., 2009), we studied its effects on quinpirole-induced heterologous sensitization in HEK-D2L and HEK-AC6/D2 cellular models.

To study the development of heterologous sensitization of $\mathrm{AC}$, we preincubated the cells for 30 minutes with MLN4924 prior to the addition of quinpirole. Pretreatment with MLN4924 blocked heterologous sensitization of AC in both HEK-D2L and HEK-AC6/D2 cells (Fig. 5, B and C). We also determined the $\mathrm{IC}_{50}$ value of MLN4924 for inhibiting D2R-mediated heterologous sensitization of AC6 to be $6.2 \mathrm{nM}$ (Fig. 5C). This value is in close agreement with the reported potency $\left(\mathrm{IC}_{50}\right.$ value $\sim 4 \mathrm{nM}$ ) of MLN4924 for NAE inhibition (Soucy et al., 2009). Moreover, immunoblot analysis for cullin3 showed a complete block of cullin3 neddylation following pretreatment with MLN4924 in the conditions used to study heterologous sensitization of AC (Fig. 5D). Together, these results are consistent with a relationship between cullin3 neddylation and heterologous sensitization of AC. Subsequently, we also examined the effects of MLN4924 on the expression phase of heterologous sensitization of AC. In contrast to the development (MLN4924 pretreatment) studies, incubation with MLN4924 after quinpirole treatment failed to inhibit the expression phase of AC6 heterologous sensitization (Supplemental Fig. 4, A and B). These observations suggested that MLN4924 selectively blocks the development but not the expression of heterologous sensitization. We also confirmed that MLN4924 was inactive for modulating acute D2R signaling and exhibited low toxicity in HEK293 cells (Supplemental Fig. 4, C and D).

MLN4924 Blocked Heterologous Sensitization of Multiple AC Isoforms in Different Cellular Models. Next, we examined whether the effects of MLN4924 were limited to one family of ACs (group III) or to one type of $\mathrm{G} \alpha_{\mathrm{i} / \mathrm{o}}$-coupled
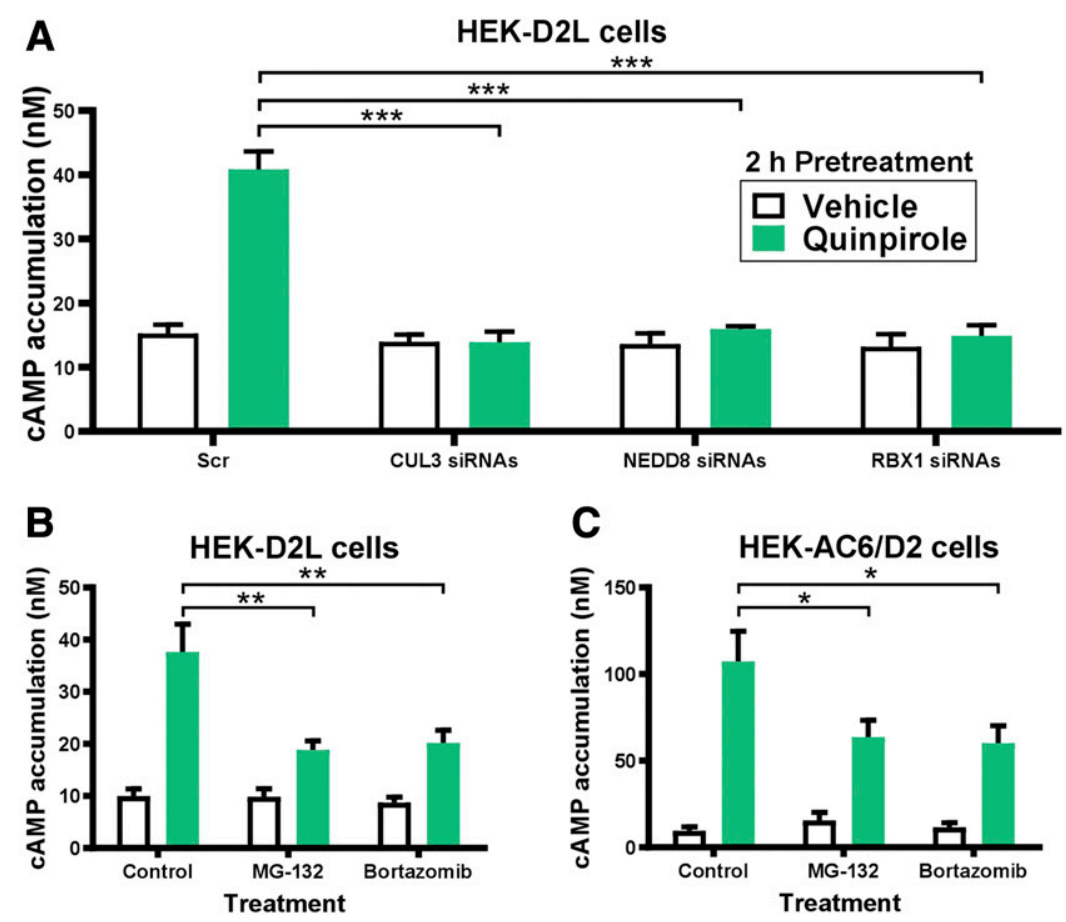

Fig. 4. Effect of siRNA for $C U L 3, N E D D 8$, or $R B X 1$ genes and MG-132 and bortezomib on heterologous sensitization of endogenous AC isoforms and AC6. (A) HEK-D2L cells were transfected with scrambled (Scr) or pooled siRNAs targeting the CUL3, NEDD8, or RBX1 genes for 72 hours. Cells were pretreated for 2 hours with vehicle or $1 \mu \mathrm{M}$ quinpirole. After pretreatment, the cells were incubated with $1 \mu \mathrm{M}$ forskolin in the presence of $1 \mu \mathrm{M}$ spiperone and $500 \mu \mathrm{M}$ IBMX for 1 hour. HEK-D2L (B) and HEK-AC6/D2 (C) cells were pretreated for 30 minutes with control (DMSO), $1 \mu \mathrm{M}$ MG132, or $1 \mu \mathrm{M}$ bortezomib before being treated with vehicle or $1 \mu \mathrm{M}$ quinpirole for 2 hours. After treatment, HEK-D2L and HEK-AC6/D2 cells were incubated with $1 \mu \mathrm{M}$ and $50 \mathrm{nM}$ forskolin, respectively, in the presence of $1 \mu \mathrm{M}$ spiperone and $500 \mu \mathrm{M}$ IBMX for 1 hour. ${ }^{*} P<0.05 ; * * P<0.01 ; * * * P<0.001$. Two-way ANOVA followed by Tukey's test. 
receptors. We used HEK293 cells expressing D2R with AC1 (HEK-AC1/D2), representing subgroup I, or AC2 (HEK-AC2/ D2), representing subgroup II. We found that pretreatment with MLN4924 also prevented heterologous sensitization of $\mathrm{AC} 1$ and $\mathrm{AC} 2$ induced by D2R activation (Fig. 6A), indicating that the role of cullin3-RING ligases in heterologous sensitization is not restricted to AC6.

Similar effects of MLN4924 were observed in experiments using cells transfected with MORs and recombinant AC5 (HEK-AC5/MOR) (Fig. 6B). Lastly, we used NG108-15 cells to examine heterologous sensitization of endogenous ACs induced by activation of endogenous $\delta$-opioid receptors (DORs). NG108-15 cells were used in the original report in 1975 that first described morphine-induced AC sensitization (Sharma et al., 1975). Consistent with our recombinant expression systems, MLN4924 pretreatment inhibited heterologous sensitization in the NG108-15 cells (Fig. 6C). Taken together, these data indicate that activated cullin3-RING ligases mediate heterologous sensitization through a common pathway shared by multiple $\mathrm{AC}$ isoforms and types of $\mathrm{G} \alpha_{\mathrm{i}} /_{\mathrm{o}}$-coupled receptors (D2, $\mu$-opioid, and $\delta$-opioid).

\section{Discussion}

Heterologous sensitization of $\mathrm{AC}$ was originally proposed to explain tolerance and withdrawal following chronic opiate administration and may be a mechanism by which cells adapt to prolonged activation of inhibitory G protein-coupled receptors (Sharma et al., 1975; Duman et al., 1988). Such an adaptive mechanism causes enhanced cAMP signaling and has been suggested to play a role in several pathologic processes, including chronic pain (Hucho and Levine, 2007), anxiety (Keil et al., 2016), and drug addiction (Chan and Lutfy, 2016). Research during the last 40 years has suggested $\mathrm{G} \alpha_{\mathrm{i}} / \mathrm{o}_{\mathrm{o}}$-coupled receptors, $\mathrm{G}$ proteins, and $\mathrm{AC}$ isoform specific processes for heterologous sensitization (Watts et al., 1998; Ammer and Christ, 2002; Clark et al., 2004; Vortherms et al., 2006); however, fundamental underlying mechanisms of this phenomenon remain unknown. We designed, optimized, and performed a cell-based genome-wide RNAi screen followed by a series of validation and confirmation assays to identify a set of novel genes associated with heterologous sensitization of AC. Intriguingly, we identified, for the first time, the specific and pivotal role of $C U L 3, N E D D 8$, and $R B X 1$ genes in heterologous sensitization of AC. Subsequent cAMP experiments with proteasome inhibitors and the specific neddylation inhibitor MLN4924 supported an important role for cullin3-RING ligases in increased activity of AC isoforms in multiple cellular models. That heterologous sensitization persists for greater than 2 hours following agonist treatment (Supplemental Fig. 5) is also consistent with the potential involvement of protein degradation.

The cullin 3 protein is a part of a seven-membered protein family (cullin 1, 2, 3, 4A, 4B, 5, and 7) that has been cloned in mammals (Sarikas et al., 2011). They scaffold
A

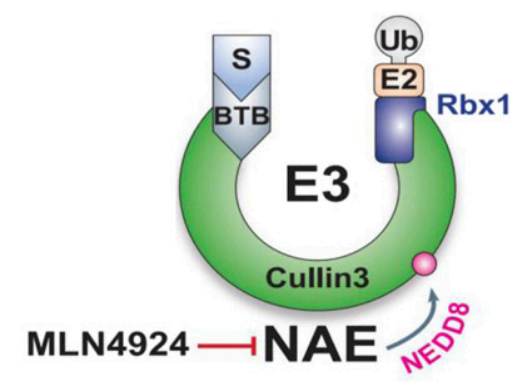

B

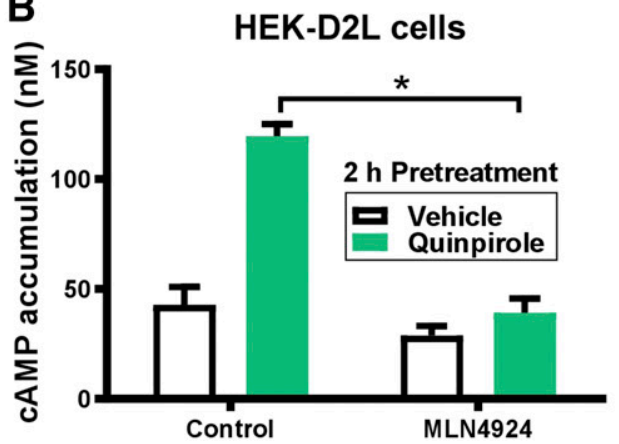

C

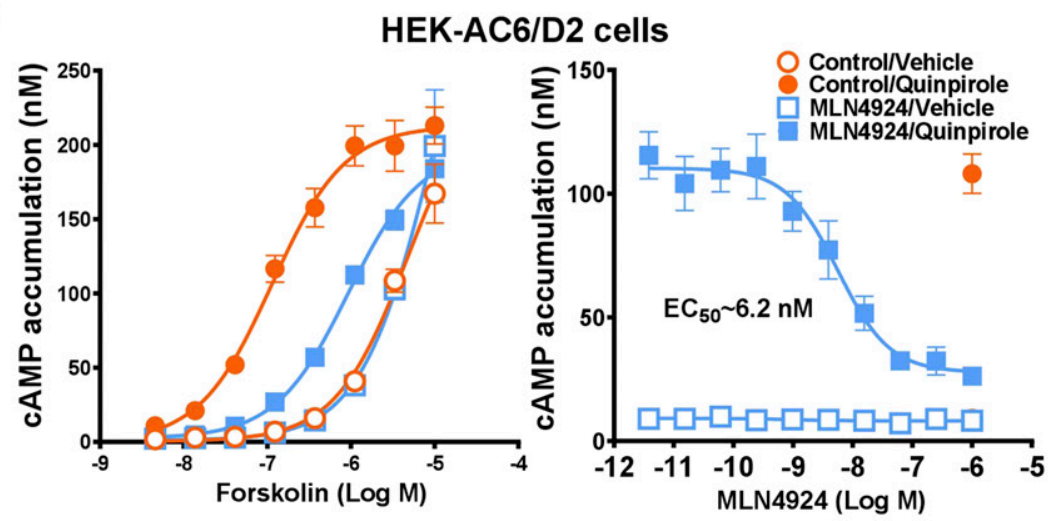

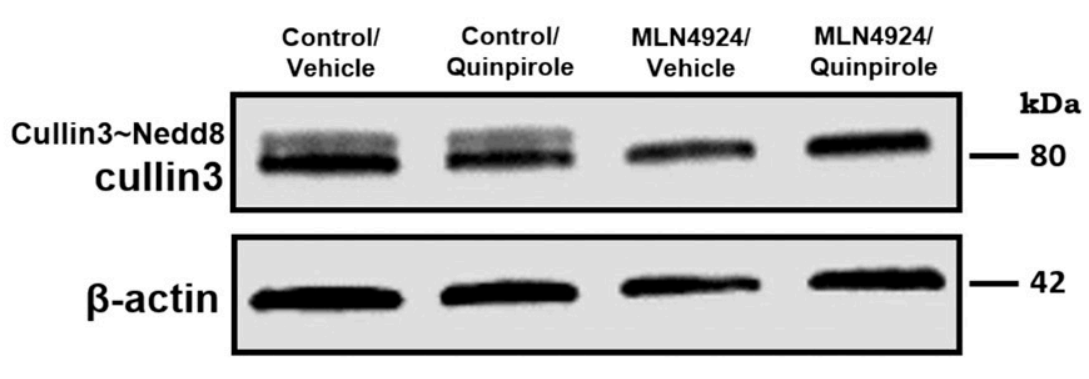

Fig. 5. Effect and potency of MLN4924 on heterologous sensitization of endogenous AC isoforms and AC6. (A) Diagram for MLN4924 inhibition of neddylation of the cullin3-RING ligase. (B) HEK-D2L cells were pretreated for 30 minutes with control (DMSO) or $1 \mu$ M MLN4924. After pretreatment, the cells were incubated for 2 hours with vehicle or $1 \mu \mathrm{M}$ quinpirole before being incubated with $1 \mu \mathrm{M}$ forskolin in the presence of $1 \mu \mathrm{M}$ spiperone and 500 $\mu$ M IBMX for 1 hour. (C) HEK-AC6/D2 cells were pretreated for 30 minutes with control (DMSO) or $1 \mu$ M MLN4924 (left panel) or with control (DMSO) or increasing concentrations of MLN4924 (right panel) before being treated with vehicle or $1 \mu \mathrm{M}$ quinpirole for 2 hours. After treatment, the cells were incubated with increasing concentrations of forskolin (left panel) or $50 \mathrm{nM}$ forskolin (right panel) in the presence of $1 \mu \mathrm{M}$ spiperone and $500 \mu \mathrm{M}$ IBMX for 1 hour. (D) HEK-AC6/D2 cells were pretreated for 30 minutes with control (DMSO) or $1 \mu$ M MLN4924 before being treated for 2 hours with vehicle or 1 $\mu \mathrm{M}$ quinpirole. Whole-cell lysates were prepared and probed with anti-Cullin3 antibody. ${ }^{*} P<0.001$. Two-way ANOVA followed by Tukey's test. 


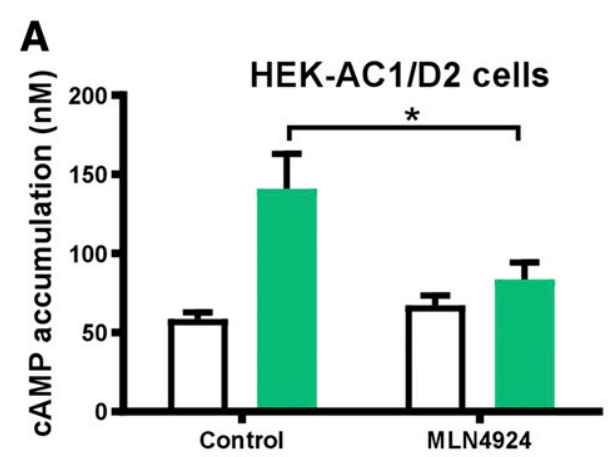

\section{B}

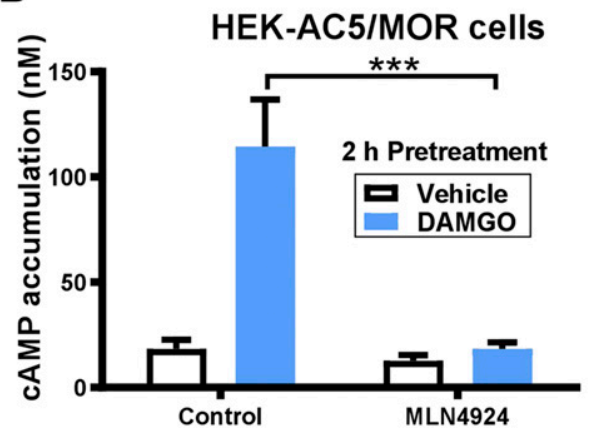

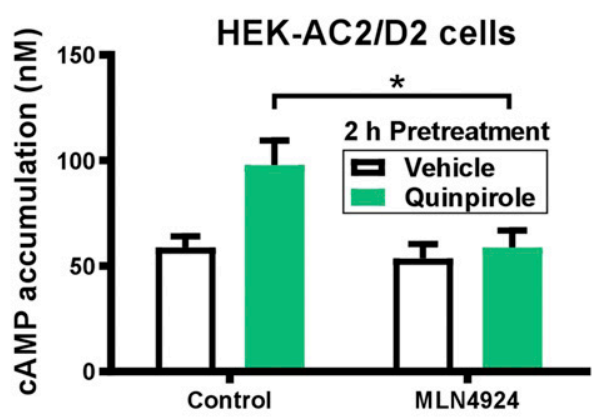

C

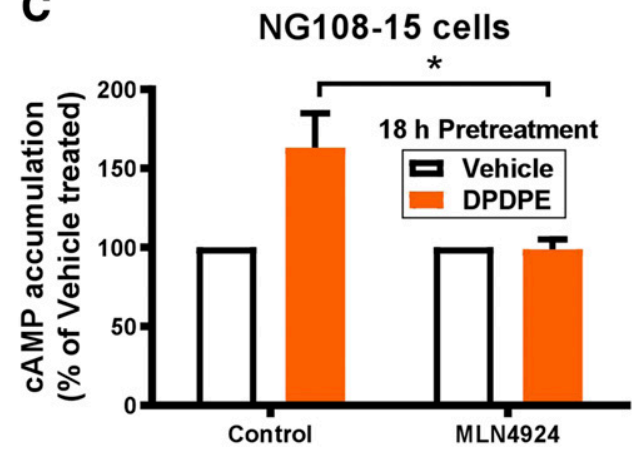

Fig. 6. Effect of MLN4924 on heterologous sensitization of recombinant and endogenous AC isoforms. (A) HEK-AC1/ D2 or HEK-AC2/D2, (B) HEK-AC5/ MOR1, or (C) NG108-15 cells were pretreated for 30 minutes with control (DMSO) or $1 \mu \mathrm{M}$ MLN4924 as indicated. (A) Cells were then treated for 2 hours with vehicle or $1 \mu \mathrm{M}$ quinpirole before being incubated with $1 \mu \mathrm{M}$ A23187 (for $\mathrm{AC} 1$ ) or $500 \mathrm{nM}$ phorbol 12-myristate 13acetate (for AC2), respectively, in the presence of $1 \mu \mathrm{M}$ spiperone and $500 \mu \mathrm{M}$ IBMX for 1 hour. (B) HEK-AC5/MOR cells were treated for 2 hours with vehicle or 1 $\mu$ M DAMGO (MOR agonist) before being incubated with $1 \mu \mathrm{M}$ forskolin in the presence of $1 \mu \mathrm{M}$ naltrexone (MOR antagonist) and $500 \mu \mathrm{M}$ IBMX for 1 hour. (C) NG108-15 cells were treated for 18 hours with vehicle or $1 \mu \mathrm{M}\left[\mathrm{D}-\mathrm{Pen}^{2}\right.$, D-Pen ${ }^{5}$ ] enkephalin (DOR agonist) before being incubated with $1 \mu \mathrm{M}$ forskolin in the presence of $1 \mu \mathrm{M}$ naltrindole (DOR antagonist) and $500 \mu \mathrm{M}$ IBMX for 1 hour. $* P<0.05 ; * * * P<0.001$. Two-way ANOVA followed by Tukey's test. adaptor proteins and the RING-box proteins on their N- and C-terminal, respectively, to comprise the largest family of E3 ubiquitin CRLs (Sarikas et al., 2011). There are two RING box proteins, RBX1 and RBX2 (also known as ROC1 and ROC2, respectively), that recruit ubiquitin-bonded E2 enzymes. Cullin5 associates with RBX2, whereas all the other cullins associate with RBX1 (Seol et al., 1999). It has been demonstrated that different adaptor proteins associate with certain cullins, directly or in combination with specific substrate recognition proteins, to recruit the substrates for ubiquitination. For example, cullin3 binds to several BTB domain-containing proteins that act as substrate recognition proteins (Xu et al., 2003). The fully assembled CRL complex is functionally inactive and requires neddylation, an attachment of the NEDD8 protein at a specific lysine residue on the cullins to activate the ubiquitin ligase function (Pan et al., 2004).

Cullin3-RING ligases play pivotal roles in cancer, cell cycle regulation, and cell stress by mediating protein ubiquitination and subsequent proteasome-involved protein degradation (Andérica-Romero et al., 2013). We demonstrated that pretreatment with the proteasome inhibitors MG-132 or bortezomib significantly inhibited heterologous sensitization of endogenous AC and AC6. Combined with our genetic data, these observations suggest that cullin3-RING-proteasome-mediated protein degradation is important for the development of AC sensitization. Our results are in line with other studies showing that the proteasome inhibitors MG-132 and lactacystin could inhibit addiction-related behaviors induced by morphine or amphetamine (Mao et al., 2009; Massaly et al., 2013). Specifically, proteasome-mediated degradation of the crucial N-methyl D-aspartate receptor subtype 2Banchoring proteins plays a critical role in regulating behavioral sensitization to amphetamine (Mao et al., 2009). However, it remains unknown which $\mathrm{E} 3$ ligases are involved in this process. Because AC sensitization may be involved in drug addiction, our findings may also suggest that cullin3-RING ligases are potentially involved in this process. Nevertheless, further studies are warranted to verify this hypothesis.

In addition to proteasome inhibitors, we also demonstrated that pretreatment with MLN4924 mimicked the effect of gene knockdown of CUL3, NEDD8, and RBX1 in blocking heterologous sensitization of endogenous and recombinant $\mathrm{AC}$ isoforms, including AC1, AC2, AC5, and AC6. MLN4924 inactivates CRLs through formation of a covalent NEDD8MLN4924 adduct (Brownell et al., 2010), and our Western blot analysis confirmed that MLN4924 blocked the neddylation of cullin3 during the development of heterologous sensitization. These data strongly support the notion that CRLs, especially cullin3-RING ligases, play a critical role in regulating AC sensitization. Moreover, it should be noted that pretreatment with MLN4924 abolished AC sensitization without changing the acute AC6 activity. This was in contrast to the transfection of siRNAs targeting $C U L 3, N E D D 8$, or $R B X 1$ that abolished AC6 sensitization; however, it attenuated the acute activity of AC6 as well. Thus, these results suggest that the role of the neddylation pathway in mediating $\mathrm{AC}$ sensitization is specific and robust, but cullin3-RING ligases may be involved in regulating acute $\mathrm{AC}$ activity.

The proteasome inhibitor bortezomib is a Food and Drug Administration-approved anticancer drug. Similarly, the specific neddylation inhibitor MLN4924 was discovered via high-throughput screening for anticancer agents (Soucy et al., 2009) and has been advanced into several phase I-III clinical trials for solid tumors and hematologic malignancies (see https:// clinicaltrials.gov/ct2/results?term $=$ MLN4924\&Search=Search). Both agents can block the ubiquitination-proteasome system, leading to the accumulation of ubiquitinated substrates (Liao et al., 2011). As a result, those accumulated substrates induce abnormal cell-cycle progression, apoptosis, senescence, and/or autophagy to suppress the growth of cancer cells (Zhou 
et al., 2018). Although further studies are needed, our findings suggest that heterologous sensitization is a result of a neddylation-dependent proteasome-targeted loss of a proteins that normally stabilizes or inhibits AC activity. Therefore, identifying such regulatory proteins would be very interesting in the future; however, the number of cullin3-binding proteins (approximately 200 BTB proteins) and their potential substrates will make this endeavor challenging.

In summary, we provide the in vitro evidence showing, for the first time, that the neddylation and the proteasome pathway are intimately involved in the development of heterologous sensitization of AC. Our findings provide new insights regarding the molecular mechanism of AC heterologous sensitization involving neddylation and suggest a potentially new GPCR signaling pathway that could be targeted for drug discovery efforts against AC signaling pathologies.

\section{Acknowledgments}

The authors would like to thank Dr. Darci J. Trader for scientific suggestions, Drs. Trevor B. Doyle and Alexander R. French for their advice in preparing figures, and Rebecca Wendt for assistance with graphical design.

\section{Authorship Contributions}

Participated in research design: Ding, Ejendal, Soto-Velasquez, Hayes, Santoro, Larsen, Watts.

Conducted experiments: Ding, Ejendal, Soto-Velasquez, Hayes, Santoro.

Performed data analysis: Ding, Ejendal, Soto-Velasquez, Hayes, Santoro, Larsen, Watts.

Wrote or contributed to the writing of the manuscript: Ding, Ejendal, Soto-Velasquez, Santoro, Larsen, Watts.

\section{References}

Aloisi G, Silvano E, Rossi M, Millan MJ, and Maggio R (2011) Differential induction of adenylyl cyclase supersensitivity by antiparkinson drugs acting as agonists at dopamine D1/D2/D3 receptors vs D2/D3 receptors only: parallel observations from co-transfected human and native cerebral receptors. Neuropharmacology 60 $439-445$.

Ammer $\mathrm{H}$ and Christ TE (2002) Identity of adenylyl cyclase isoform determines the $\mathrm{G}$ protein mediating chronic opioid-induced adenylyl cyclase supersensitivity. J Neurochem 83:818-827.

Andérica-Romero AC, González-Herrera IG, Santamaría A, and Pedraza-Chaverri J (2013) Cullin 3 as a novel target in diverse pathologies. Redox Biol 1: 366-372.

Brownell JE, Sintchak MD, Gavin JM, Liao H, Bruzzese FJ, Bump NJ, Soucy TA, Milhollen MA, Yang X, Burkhardt AL, et al. (2010) Substrate-assisted inhibition of ubiquitin-like protein-activating enzymes: the NEDD8 E1 inhibitor MLN4924 forms a NEDD8-AMP mimetic in situ. Mol Cell 37:102-111.

Brust TF, Conley JM, and Watts VJ (2015) G $\alpha(\mathrm{i} / \mathrm{o})$-coupled receptor-mediated sensitization of adenylyl cyclase: 40 years later. Eur J Pharmacol 763 (Pt B):223-232. Chan P and Lutfy K (2016) Molecular changes in opioid addiction: the role of adenylyl cyclase and cAMP/PKA system. Prog Mol Biol Transl Sci 137:203-227.

Chester JA, Mullins AJ, Nguyen CH, Watts VJ, and Meisel RL (2006) Repeated quinpirole treatments produce neurochemical sensitization and associated behavioral changes in female hamsters. Psychopharmacology (Berl) 188:53-62.

Clark MJ, Neubig RR, and Traynor JR (2004) Endogenous regulator of G protein signaling proteins suppress Galphao-dependent, $\mu$-opioid agonist-mediated adenylyl cyclase supersensitization. J Pharmacol Exp Ther 310:215-222.

Conley JM and Watts VJ (2013) Differential effects of AGS3 expression on D(2L) dopamine receptor-mediated adenylyl cyclase signaling. Cell Mol Neurobiol 33 (4): 551-558, doi: 10.1007/s10571-013-9925-8 23504261.

Cumbay MG and Watts VJ (2001) Heterologous sensitization of recombinant adenylate cyclases by activation of $\mathrm{D}(2)$ dopamine receptors. J Pharmacol Exp Ther 297:1201-1209.
Dessauer CW, Watts VJ, Ostrom RS, Conti M, Dove S, and Seifert R (2017) International Union of Basic and Clinical Pharmacology. CI. Structures and small molecule modulators of mammalian adenylyl cyclases. Pharmacol Rev 69:93-139.

Duman RS, Tallman JF, and Nestler EJ (1988) Acute and chronic opiate-regulation of adenylate cyclase in brain: specific effects in locus coeruleus. J Pharmacol Exp Ther 246:1033-1039.

Ejendal KFK, Dessauer CW, Hébert TE, and Watts VJ (2012) Dopamine D(2) receptor-mediated heterologous sensitization of AC5 requires signalosome assembly. J Signal Transduct 2012:210324

Hori T, Osaka F, Chiba T, Miyamoto C, Okabayashi K, Shimbara N, Kato S, and Tanaka K (1999) Covalent modification of all members of human cullin family proteins by NEDD8. Oncogene 18:6829-6834.

Hucho T and Levine JD (2007) Signaling pathways in sensitization: toward a nociceptor cell biology. Neuron 55:365-376.

Jacob RT, Larsen MJ, Larsen SD, Kirchhoff PD, Sherman DH, and Neubig RR (2012) MScreen: an integrated compound management and high-throughput screening data storage and analysis system. J Biomol Screen 17:1080-1087.

Jin J, Ang XL, Shirogane T, and Wade Harper J (2005) Identification of substrates for F-box proteins. Methods Enzymol 399:287-309.

Keil MF, Briassoulis G, Stratakis CA, and Wu TJ (2016) Protein kinase A and anxiety-related behaviors: a mini-review. Front Endocrinol (Lausanne) 7:83.

Liao H, Liu XJ, Blank JL, Bouck DC, Bernard H, Garcia K, and Lightcap ES (2011) Quantitative proteomic analysis of cellular protein modulation upon inhibition of the NEDD8-activating enzyme by MLN4924. Mol Cell Proteomics 10:M111.009183.

Mao L-M, Wang W, Chu X-P, Zhang G-C, Liu X-Y, Yang Y-J, Haines M, Papasian CJ, Fibuch EE, Buch S, et al. (2009) Stability of surface NMDA receptors controls synaptic and behavioral adaptations to amphetamine. Nat Neurosci 12:602-610.

Massaly N, Dahan L, Baudonnat M, Hovnanian C, Rekik K, Solinas M, David V, Pech S, Zajac J-M, Roullet P, et al. (2013) Involvement of protein degradation by the ubiquitin proteasome system in opiate addictive behaviors. Neuropsychopharmacology 38:596-604

Ohta T, Michel JJ, Schottelius AJ, and Xiong Y (1999) ROC1, a homolog of APC11, represents a family of cullin partners with an associated ubiquitin ligase activity. Mol Cell 3:535-541.

Pan Z-Q, Kentsis A, Dias DC, Yamoah K, and Wu K (2004) Nedd8 on cullin: building an expressway to protein destruction. Oncogene 23:1985-1997.

Sarikas A, Hartmann T, and Pan Z-Q (2011) The cullin protein family. Genome Biol 12:220.

Sato M, Gettys TW, and Lanier SM (2004) AGS3 and signal integration by Galpha(s)- and Galpha(i)-coupled receptors: AGS3 blocks the sensitization of adenylyl cyclase following prolonged stimulation of a Galpha(i)-coupled receptor by influencing processing of Galpha(i). J Biol Chem 279 (14):13375-13382, doi: 10.1074/jbc.M312660200 14726514.

Seol JH, Feldman RMR, Zachariae W, Shevchenko A, Correll CC, Lyapina S, Chi Y, Galova M, Claypool J, Sandmeyer S, et al. (1999) Cdc53/cullin and the essential Hrt1 RING-H2 subunit of SCF define a ubiquitin ligase module that activates the E2 enzyme Cdc34. Genes Dev 13:1614-1626.

Sharma SK, Klee WA, and Nirenberg M (1975) Dual regulation of adenylate cyclase accounts for narcotic dependence and tolerance. Proc Natl Acad Sci USA 72: 3092-3096.

Soucy TA, Smith PG, Milhollen MA, Berger AJ, Gavin JM, Adhikari S, Brownell JE, Burke KE, Cardin DP, Critchley S, et al. (2009) An inhibitor of NEDD8-activating enzyme as a new approach to treat cancer. Nature 458:732-736.

Varga EV, Rubenzik M, Grife V, Sugiyama M, Stropova D, Roeske WR, and Yamamura HI (2002) Involvement of Raf-1 in chronic $\delta$-opioid receptor agonist-mediated adenylyl cyclase superactivation. Eur J Pharmacol 451:101-102.

Vortherms TA, Nguyen CH, Bastepe M, Jüppner H, and Watts VJ (2006) D2 dopamine receptor-induced sensitization of adenylyl cyclase type 1 is $G \alpha(s)$ independent. Neuropharmacology 50:576-584.

Watts VJ and Neve KA (1996) Sensitization of endogenous and recombinant adenylate cyclase by activation of D2 dopamine receptors. Mol Pharmacol 50:966-976.

Watts VJ and Neve KA (2005) Sensitization of adenylate cyclase by Galpha i/o-coupled receptors. Pharmacol Ther 106:405-421.

Watts VJ, Wiens BL, Cumbay MG, Vu MN, Neve RL, and Neve KA (1998) Selective activation of Galphao by D2L dopamine receptors in NS20Y neuroblastoma cells. $J$ Neurosci 18:8692-8699.

Xu L, Wei Y, Reboul J, Vaglio P, Shin T-H, Vidal M, Elledge SJ, and Harper JW (2003) BTB proteins are substrate-specific adaptors in an SCF-like modular ubiquitin ligase containing CUL-3. Nature 425:316-321.

Yue X, Tumati S, Navratilova E, Strop D, St John PA, Vanderah TW, Roeske WR, Yamamura HI, and Varga EV (2008) Sustained morphine treatment augments basal CGRP release from cultured primary sensory neurons in a Raf-1 dependent manner. Eur J Pharmacol 584:272-277.

Zhou L, Zhang W, Sun Y, and Jia L (2018) Protein neddylation and its alterations in human cancers for targeted therapy. Cell Signal 44:92-102.

Address correspondence to: Val J. Watts, Department of Medicinal Chemistry and Molecular Pharmacology, 575 Stadium Mall Dr., Purdue University, West Lafayette, IN 47907. E-mail: wattsv@purdue.edu 